Received 01/22/2022 Review began 02/02/2022 Review ended 02/07/2022 Published 02/16/2022

\section{(c) Copyright 2022}

Karan et al. This is an open access article distributed under the terms of the Creative Commons Attribution License CC-BY 4.0., which permits unrestricted use, distribution, and reproduction in any medium, provided the original author and source are credited.

\title{
A Breathtaking Hernia: A Giant Hiatal Hernia Masquerading as Poorly Controlled Asthma
}

\author{
Abhinav Karan ${ }^{1}$, Hui Jun Guo ${ }^{1}$, Kintin $\mathrm{Ng}^{1}$, Christopher Izzo ${ }^{1}$ \\ 1. Internal Medicine, University of Florida College of Medicine, Jacksonville, USA
}

Corresponding author: Abhinav Karan, abhinav.karan@jax.ufl.edu

\begin{abstract}
A 93-year-old female presented with persistent shortness of breath and wheezing since the consumption of a meal. Her past medical history is significant for a clinical diagnosis of asthma at the age of 88 years, without pulmonary function testing, complicated by several prior visits to the emergency department (ED) for recurrent exacerbations. Multiple bronchodilators in the ED provided only minimal improvement in her symptoms. Chest imaging eventually revealed a giant, fluid-filled hiatal hernia exhibiting a compressive effect on the posterior aspect of the left atrium. The etiology of the patient's airway bronchoconstriction was likely multifactorial. We hypothesize that the extrinsic, dynamic compression of the bronchial tree by the peristaltic motion of the hiatal hernia, microaspiration from gastroesophageal reflux, and peribronchial edema from left atrial compression accounted for our patient's unique presentation. An outpatient methacholine challenge test eventually excluded bronchial asthma. Although she was considered a poor surgical candidate, she has had no further recurrences of her symptoms with counseling on conservative lifestyle changes. This case serves to highlight the heterogeneity in presentations of hiatal hernias, particularly in elderly females. Furthermore, it remains prudent to maintain a broad differential for wheezing, as evidenced by our patient who was previously managed for a number of years as poorly controlled asthma.
\end{abstract}

Categories: Internal Medicine, Gastroenterology, Pulmonology

Keywords: hiatal hernia, paraesophageal hernia, sliding hernia, pulmonary edema, gerd, heart failure, asthma, recurrent wheezing

\section{Introduction}

A giant hiatal hernia presents a diagnostic and therapeutic dilemma for most clinicians, often being found incidentally on chest imaging. The vast majority of hiatal hernias are asymptomatic, however, a minority of individuals can present with symptoms of gastroesophageal reflux disease [1]. Here, we present a unique case of a patient with a giant hiatal hernia who was being managed for a number of years as poorly controlled asthma, along with a brief review of the literature.

\section{Case Presentation}

A 93-year-old female presented to the emergency department with persistent shortness of breath and wheezing since consumption of a meal. Her past medical history is significant for hypertension, osteoarthritis, and a clinical diagnosis of bronchial asthma at the age of 88 years, without prior pulmonary function testing. She describes a complicated course, with multiple visits to the emergency department for recurrent episodes of dyspnea and wheezing despite bronchodilator and inhaled corticosteroid therapy. She is compliant with both a short-acting beta-agonist inhaler and an inhaled corticosteroid at home, which she uses prudently, and has received multiple courses of prednisone for presumed asthma exacerbations in her prior visits to the emergency department. She notes that she often presents to the ED for significant shortness of breath and audible wheezing, usually after a large meal, that only resolves after prolonged bronchodilator nebulization. She had not been prescribed any angiotensin-converting enzyme inhibitors, proton pump inhibitors, or $\mathrm{H} 2$ receptor blockers prior to presentation.

At the time of presentation, her vital signs were notable for tachycardia with a pulse of 110, and hypoxia with oxygen saturation of $86 \%$, requiring placement of full-face bilevel positive airway pressure for titration of oxygen saturation. Her physical examination was notable for diffuse, loud wheezing auscultated throughout lung fields bilaterally, a 2/6 pansystolic murmur along the left sternal border, and mild bilateral lower limb edema. Point of care ultrasound revealed a grossly preserved ejection fraction, but some leftward bowing of the interventricular septum. Her complete blood count and comprehensive metabolic profile were unremarkable, with an N-terminal pro-B-type natriuretic peptide (NT-proBNP) of $877 \mathrm{pg} / \mathrm{ml}$ (reference range: $0-450 \mathrm{pg} / \mathrm{ml})$.

In the emergency department, she initially received continuous nebulizers and oxygen therapy with only mild improvement in symptoms. A chest x-ray (CXR) was performed, which demonstrated mild interstitial ground glass opacities bilaterally concerning pulmonary edema, and a faint, round opacity in the retrocardiac space (Figure 1 ). She then received $20 \mathrm{mg}$ of intravenous furosemide with a dramatic reduction 


\section{Cureus}

in wheezing and resolution of her hypoxia, with oxygen saturations above $95 \%$ on minimal oxygen therapy. A presumptive diagnosis of decompensated heart failure was made and the patient was admitted for further management. At that time, primary asthma was low on the differential due to the atypical age of diagnosis, lack of confirmatory pulmonary function testing, poor response to bronchodilator and corticosteroid therapy, and the unusual trigger of wheezing on meal consumption. Her wheezing was initially presumed to be secondary to cardiac asthma due to her excellent response to diuretic therapy. A swallow study was done which excluded signs of aspiration.

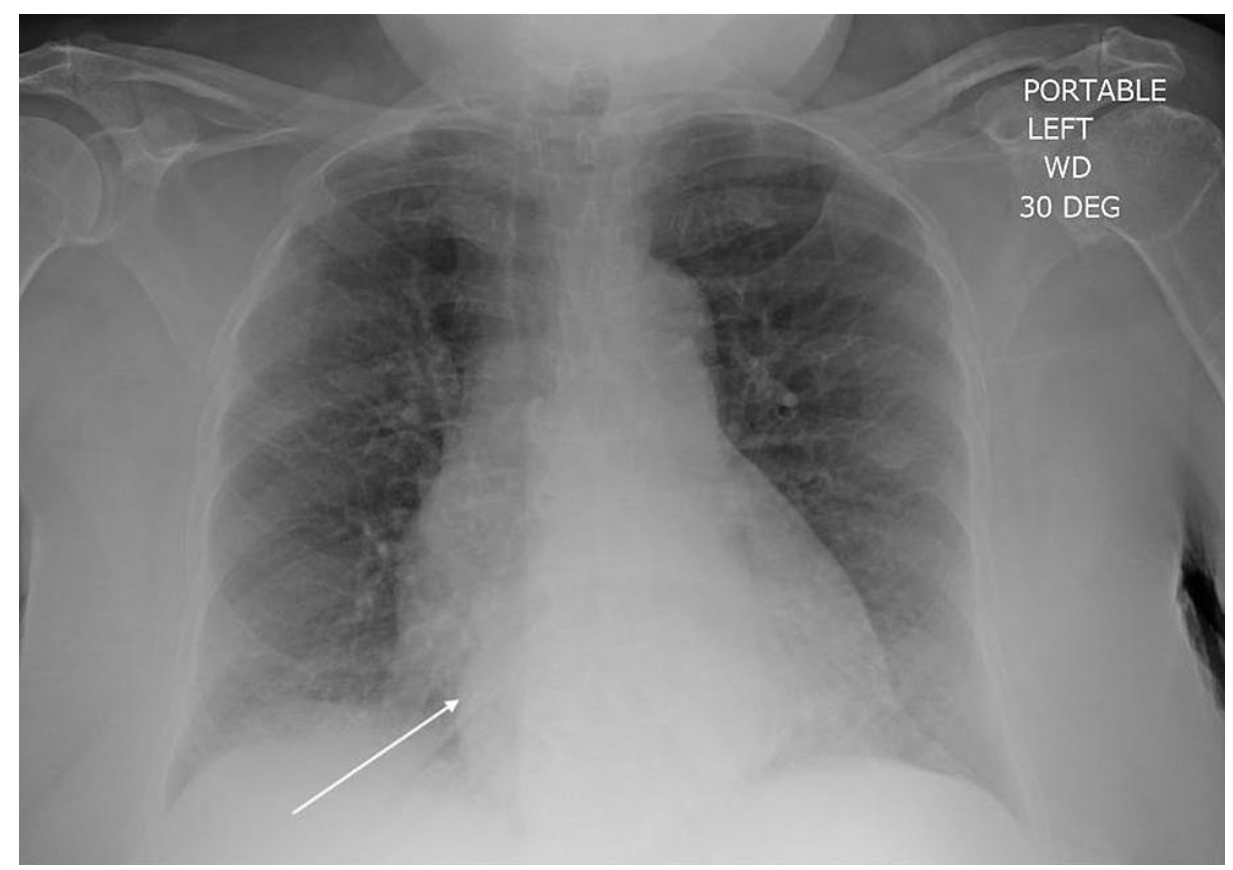

FIGURE 1: Chest x-ray showing outline of retrocardiac opacity and mild interstitial ground glass opacities bilaterally.

Arrow demonstrates the extrinsic compression of the left atrium by the giant hiatal hernia.

Due to persistent tachycardia and initial presentation of hypoxia, there was a concern for a pulmonary embolism, so a computed tomography pulmonary angiogram study (CTPA) was ordered and no emboli were found. However, it did reveal right ventricular enlargement and most notably, a distended, fluid-filled giant hiatal hernia exerting extrinsic mass effect on the posterior aspect of her heart, particularly the left atrium (Figures 2-5). 


\section{Cureus}

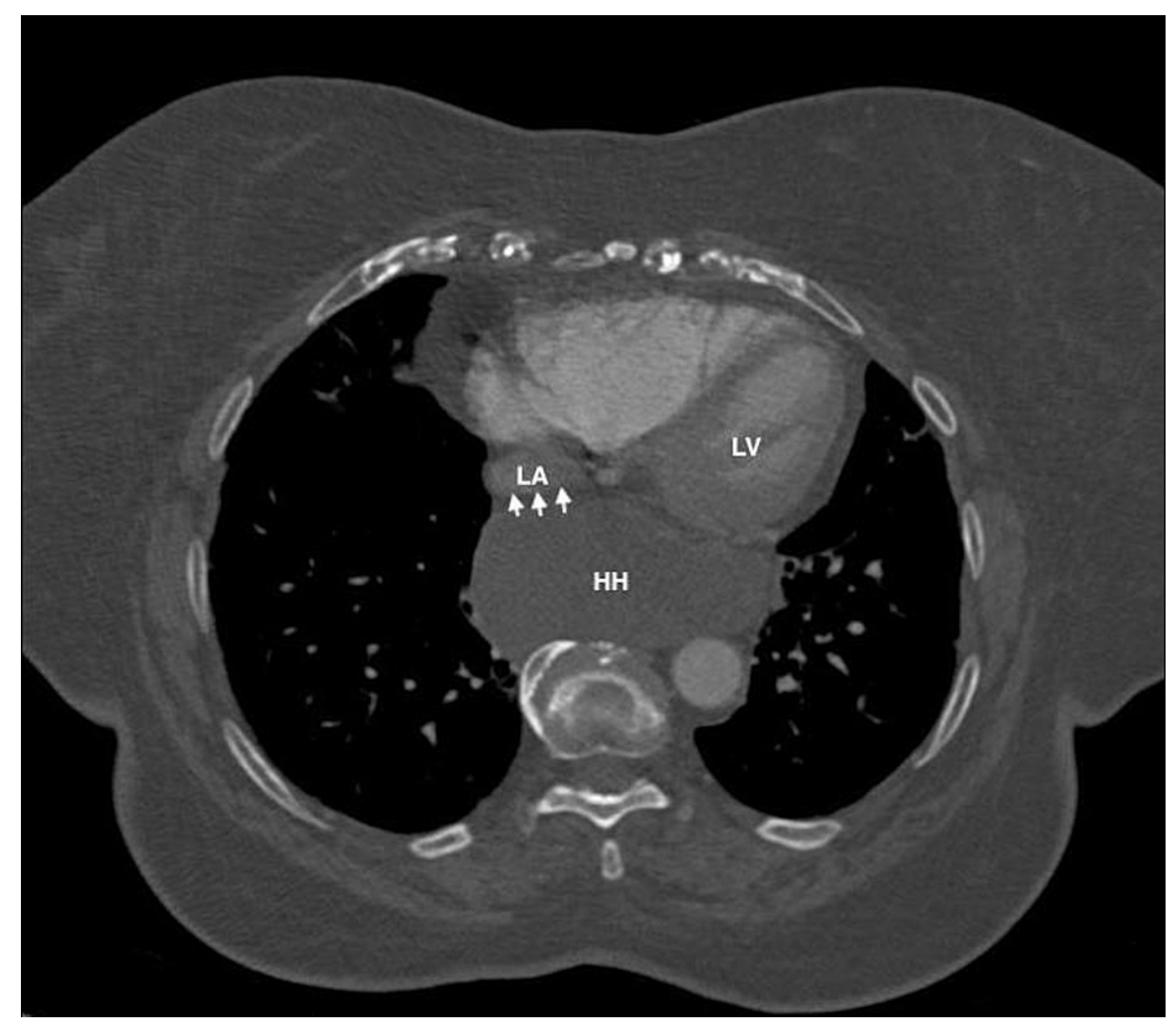

FIGURE 2: Axial view of CT chest showing compression of left atrium by a giant hiatal hernia.

Arrows demonstrating the extrinsic compression of the left atrium by the giant hiatal hernia

LA: left atrium; $\mathrm{HH}$ : hiatal hernia; LV: left ventricle 


\section{Cureus}

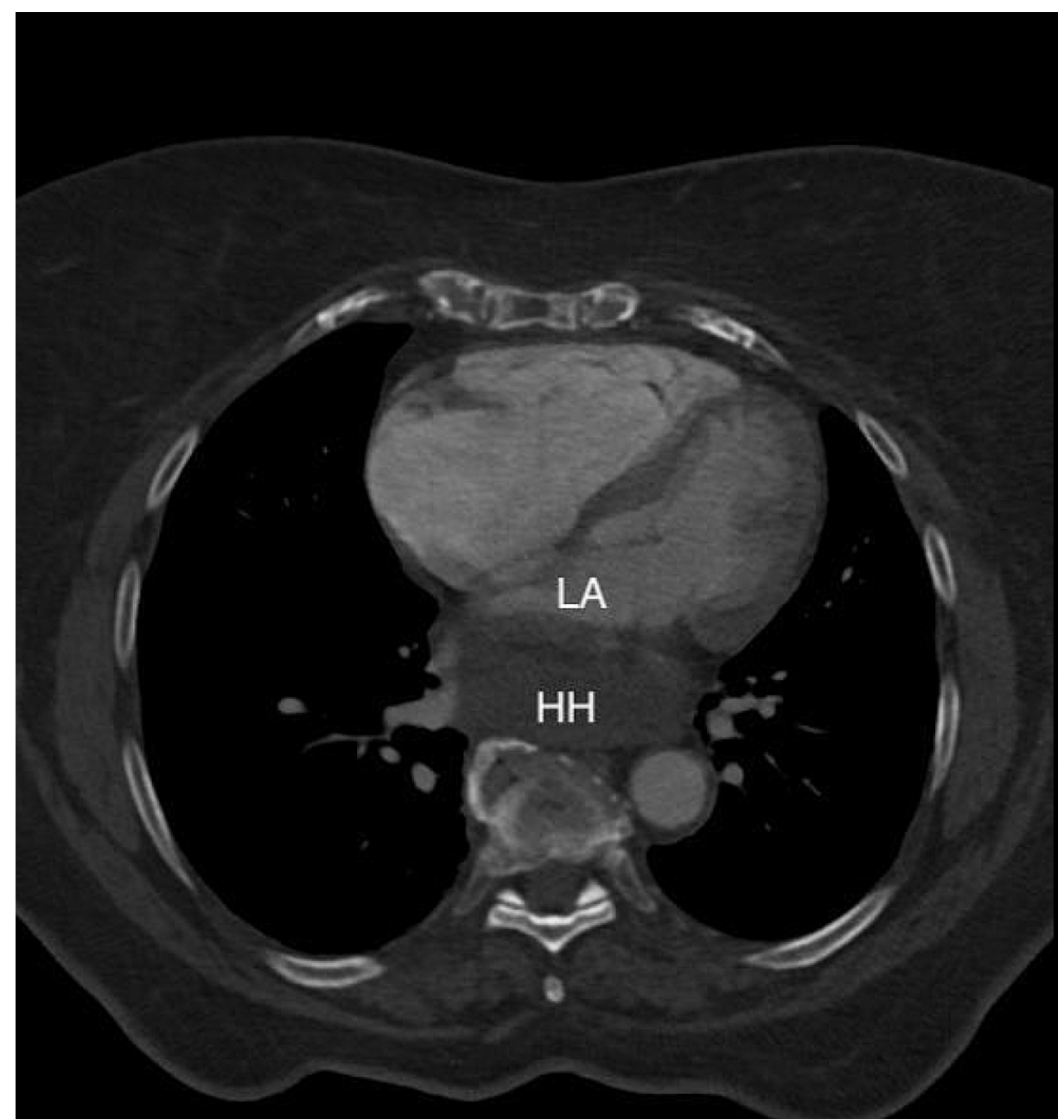

FIGURE 3: Alternate axial view of CT chest with compression of left atrium by a giant hiatal hernia.

LA: left atrium; HH: hiatal hernia 


\section{Cureus}

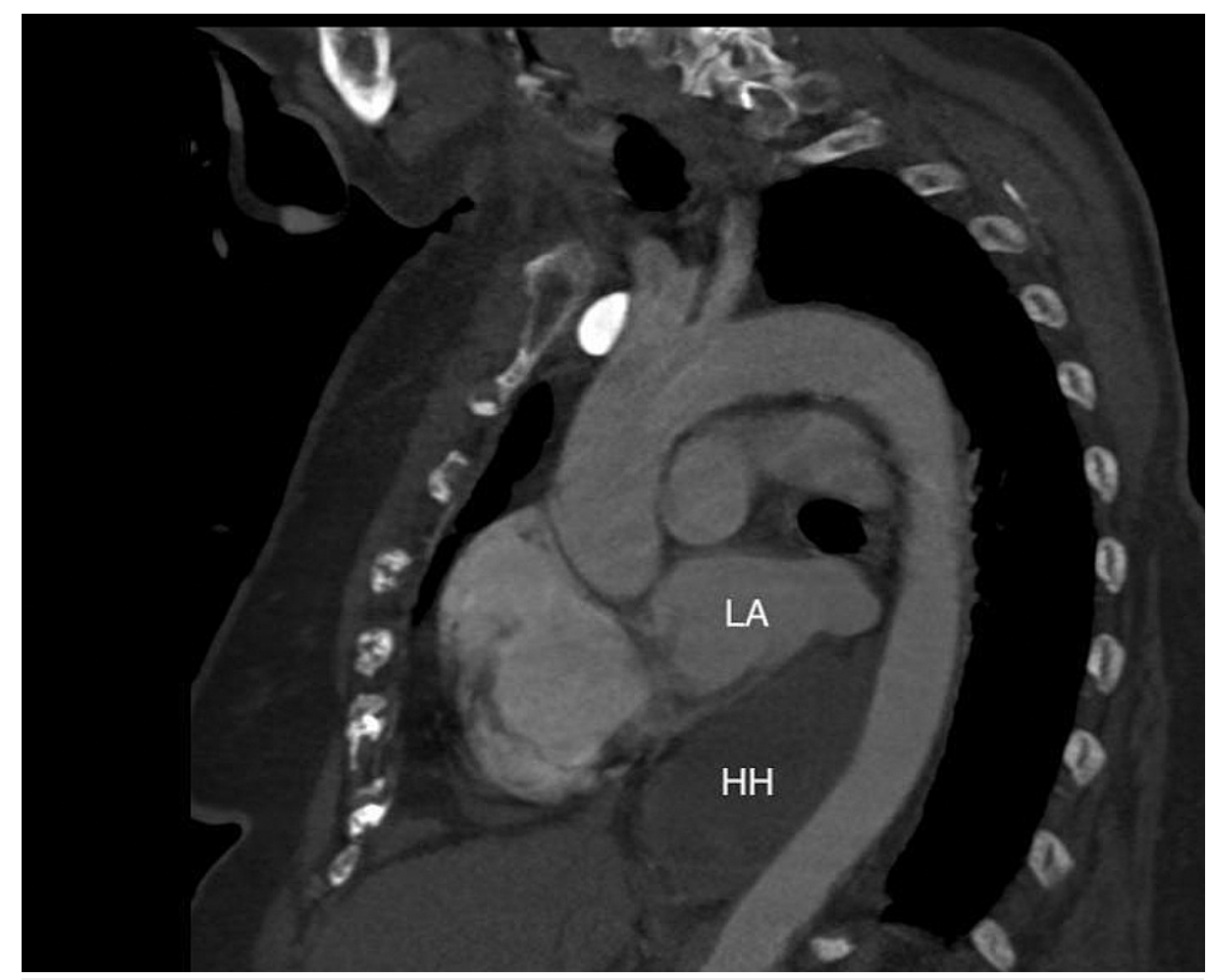

FIGURE 4: Sagittal view of CT chest with compression of the posterior left atrium by a giant hiatal hernia.

LA: left atrium; $\mathrm{HH}$ : hiatal hernia 


\section{Cureus}

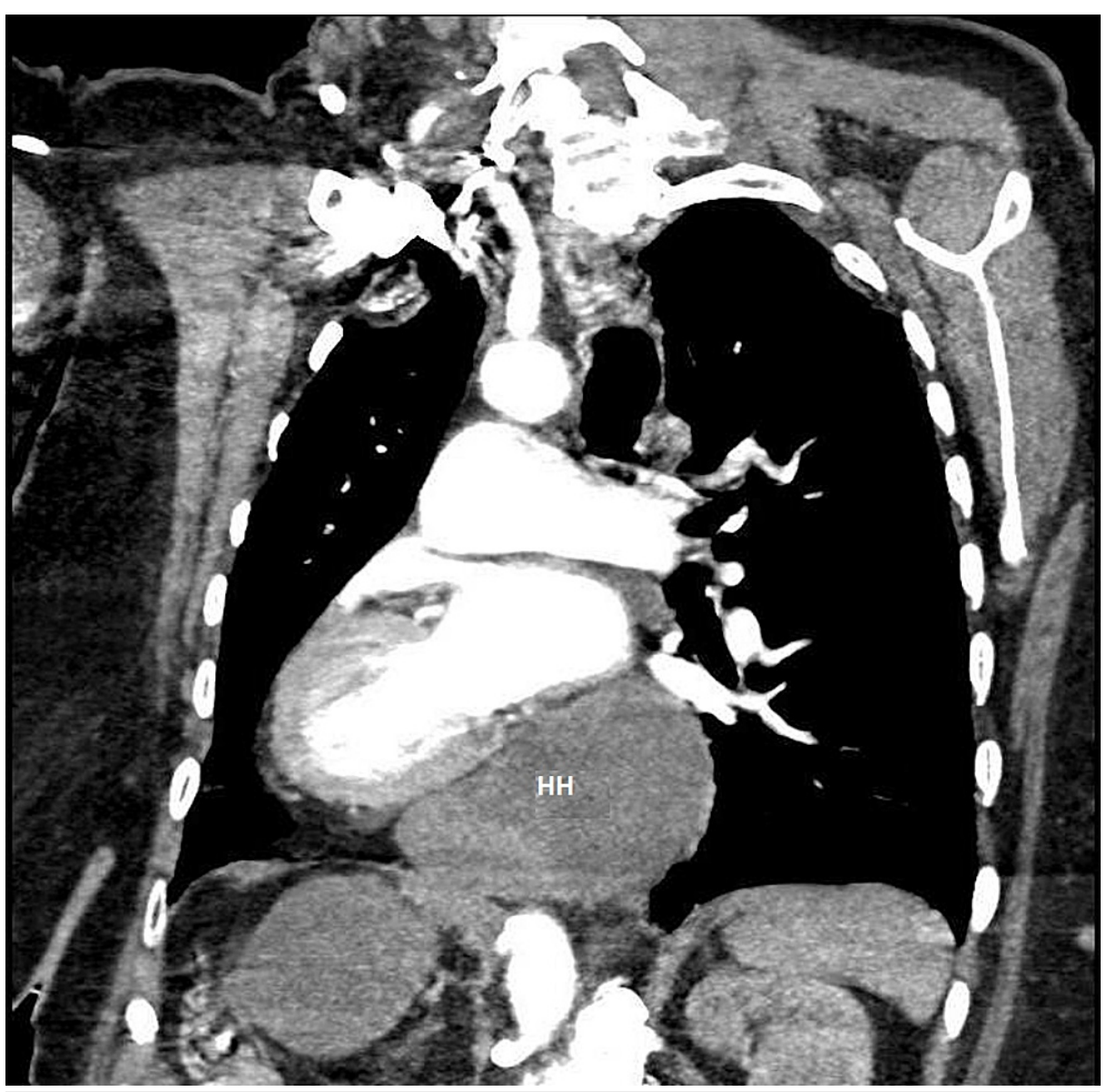

FIGURE 5: Right pulmonary artery oblique view demonstrating giant hiatal hernia with extrinsic compression of left atrium and left ventricle.

$\mathrm{HH}$ : hiatal hernia

A formal transthoracic echocardiogram (TTE) revealed an ejection fraction of 60-65\%, a small left ventricular and left atrial cavity, and a visible hiatal hernia in the subxiphoid view (Figure 6). An increased pulmonary artery systolic pressure of $51 \mathrm{mmHg}$, with moderate tricuspid regurgitation and an enlarged right ventricle, was also noted. She was referred for surgical intervention; however, due to her age and comorbidities, she was deemed a poor surgical candidate. Instead, she was counseled on conservative strategies to reduce the incidence of her symptoms. These measures included sleeping in an upright position after meals, smaller meal volumes, and avoidance of late-night meals. She was also started on proton pump inhibitor therapy and alginate-based antacid therapy. An outpatient methacholine challenge test was performed to exclude any element of bronchial asthma, which the patient did not have. On outpatient follow-up, she reported a significant improvement in her symptoms and has since had no further episodes of wheezing following the establishment of her lifestyle changes. 


\section{Cureus}

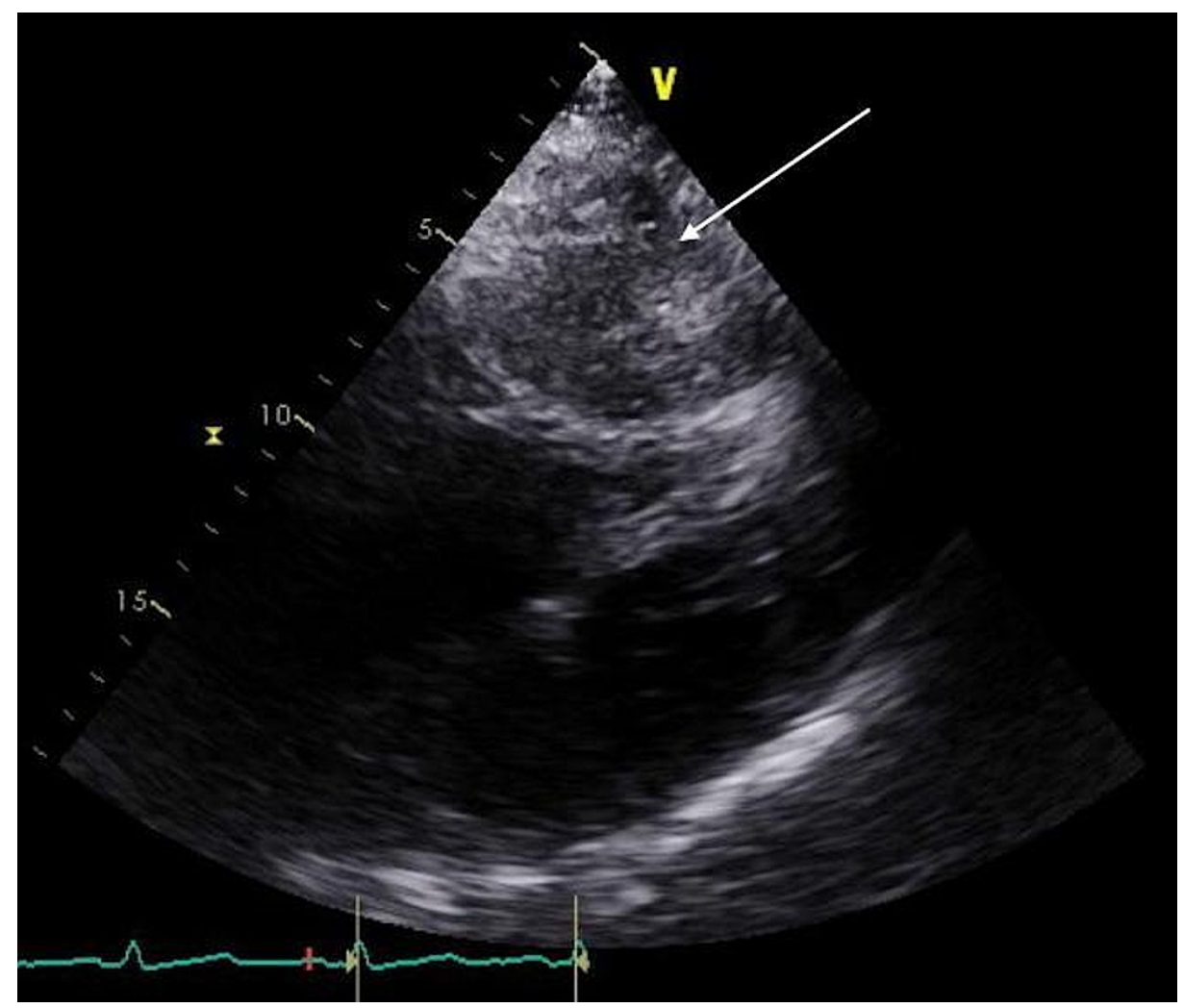

\section{FIGURE 6: Subxiphoid view of TTE with visible hiatal hernia exhibiting compressive effect on left atrium and left ventricle (arrow).}

TTE: transthoracic echocardiogram

\section{Discussion}

A uniform definition for a giant hiatal hernia (HH) does not exist yet. While they may be variously defined, there is some agreement that they refer to hernias in which $>30-50 \%$ of the stomach lies within the thoracic cavity, with or without any abdominal viscera [2]. They are rare, accounting for $0.3 \%$ of all hiatal hernias, and while their presentation sounds dramatic, the majority of these cases are either asymptomatic or in those very few individuals, present with symptoms of gastrointestinal reflux disease, most commonly being found incidentally on chest imaging performed for another indication as with our case [2].

Hiatal hernias are generally divided into four different types based on their mechanism and contents within the hiatal hernias. Type I hiatal hernias are by far the most common, accounting for $85-95 \%$ of all cases, and occur when dilation of the diaphragmatic hiatus allows upwards herniation of the stomach cardia and the gastroesophageal junction [1]. Type II hiatal hernias are broadly referred to as paraesophageal hernias, and occur when there is an associated defect in the phrenoesophageal membrane. This results in the gastroesophageal junction remaining fixed in position due to its attachment to the preaortic fascia, but the stomach herniating adjacent to the esophagus. Type III hernias broadly have a mixed mechanism and involve components of type I and type II hernias, and type IV hernias refer to any hiatal hernia with the presence of contents other than the stomach, such as the colon, omentum, or small bowel, within the hernia sac. More than $90 \%$ of all giant hiatal hernias are type III hiatal hernias, with herniation of extra-gastric contents not being uncommon [1].

Our patient presented with the primary symptom of wheezing after consumption of meals, initially managed as asthma. The underlying mechanism of this presentation warrants further discussion. In our case, it is likely that the extrinsic compression of the left atrium by the distended hiatal hernia resulted in a mechanical elevation in the pulmonary and right-sided cardiac pressures leading to both her mild pulmonary and peripheral edema. The etiology of her airway bronchoconstriction is likely multifactorial. We hypothesized that the extrinsic, dynamic compression of her bronchial tree from the peristaltic motion of the distended hiatal hernia, particularly on the consumption of meals, likely caused intermittent airway obstruction mimicking that of asthma exacerbation. In addition, there is likely a component of microaspiration from gastroesophageal reflux not detected on her swallowing studies, and peribronchial edema from the significant extrinsic left atrial compression by her giant hiatal hernia. 


\section{Cureus}

On review of the current literature on patients with a giant hiatal hernia presenting with primary respiratory complaints, without gastrointestinal symptoms, only a handful of case reports are noted, and none with the primary symptom of recurrent episodes of wheezing. These are summarized in Table 1 below [3-7]. While a small cohort, some interesting observations about the trends in presentations can be observed. As with our patient, the majority of patients presenting with atypical symptoms of a hiatal hernia are elderly, with the majority above the age of 80 years and notable female predominance. The reasoning behind this apparent trend is unknown and certainly represents a point of further research on hiatal hernias. Furthermore, while clinicians should be aware of this heterogeneity in presentations, epidemiological studies are necessary to determine whether this observed trend is statistically significant. The impact of a giant hiatal hernia on pulmonary function testing is recognized, with some literature demonstrating that surgical repair of a giant hiatal hernia can result in the improvement of a patient's forced expiratory volume in 1 second (FEV1) by $>20 \%$, with a positive correlation between the size of the giant hiatal hernia, and degree of improvement in FEV1 [8]. There is also improvement in FVC and TLC, suggesting that surgical management of symptomatic giant hiatal hernias is an effective modality for therapy [8].

\begin{tabular}{|c|c|c|c|c|c|}
\hline Author & $\begin{array}{l}\text { Mirdamadi } \\
\text { and Arasteh } \\
\text { [3] }\end{array}$ & Torres et al. [4] & Chou and Su [5] & Sahin et al. [6] & Wongrakpanich et al. [7] \\
\hline Year & 2010 & 2013 & 2014 & 2015 & 2016 \\
\hline Age (years) & 78 & 82 & 86 & 84 & 88 \\
\hline Gender & Female & Female & Female & Female & Female \\
\hline $\begin{array}{l}\text { Presenting } \\
\text { symptoms }\end{array}$ & $\begin{array}{l}\text { Paroxysmal } \\
\text { nocturnal } \\
\text { dyspnea }\end{array}$ & Exertional dyspnea & $\begin{array}{l}\text { Exertional } \\
\text { dyspnea }\end{array}$ & Progressive dyspnea & Progressive dyspnea \\
\hline Chest x-ray & $\begin{array}{l}\text { Large } \\
\text { epicardial fat } \\
\text { pad }\end{array}$ & N/A & $\begin{array}{l}\text { Cardiomegaly } \\
\text { with mediastinal } \\
\text { widening }\end{array}$ & $\begin{array}{l}\text { Mediastinal widening with } \\
\text { retrocardiac mass and air- } \\
\text { fluid level }\end{array}$ & Opacity in left lower lobe \\
\hline CT chest & $\begin{array}{l}\text { Large hiatal } \\
\text { hernia }\end{array}$ & $\begin{array}{l}\text { Hiatal herniation } \\
\text { without any structural } \\
\text { lung disease }\end{array}$ & Hiatal hernia & $\begin{array}{l}\text { Large hiatal hernia with mild } \\
\text { compression of the left } \\
\text { atrium }\end{array}$ & $\begin{array}{l}\text { Giant hiatal hernia } \\
\text { containing stomach, } \\
\text { pancreas, duodenum }\end{array}$ \\
\hline $\begin{array}{l}\text { Management } \\
\text { and outcome }\end{array}$ & $\mathrm{N} / \mathrm{A}$ & $\begin{array}{l}\text { Patient refused surgical } \\
\text { management }\end{array}$ & $\begin{array}{l}\text { Patient refused } \\
\text { surgical } \\
\text { management }\end{array}$ & $\begin{array}{l}\text { Patient refused surgical } \\
\text { management }\end{array}$ & $\begin{array}{l}\text { Patient refused surgical } \\
\text { management }\end{array}$ \\
\hline
\end{tabular}

TABLE 1: Characteristics of patients described in prior case reports of patients with giant hiatal hernias presenting with respiratory complaints without gastrointestinal symptoms.

For patients who refused surgery, or are poor surgical candidates due to age and existing comorbidities, there are still benefits to conservative management. These include a reduction in meal volumes, remaining upright after meals, and the addition of a proton pump inhibitor. These strategies are typically effective for the majority of patients with a type I hiatal hernia, where surgery is not typically warranted. In our case, it was theorized that small volume meals will aid in the reduction of the degree of peristaltic dilation of the hiatal hernia that occurs with meal consumption, the primary trigger for her episodes of wheezing. Proton pump inhibitor therapy will be effective in reducing any events of microaspiration from underlying gastroesophageal reflux from the underlying hiatal hernia. Additionally, arginate-based-suspensions as an adjunct to proton pump inhibitor therapy is frequently performed and has been shown to decrease acid reflux events within the first hour of administration [9]. This is presumed beneficial for our patient whose major trigger for wheezing was meal consumption.

While a giant hiatal hernia has previously been reported very infrequently to present atypically with acute heart failure [10], arrhythmias, angina pectoris, or symptoms of exercise impairment [7], this case highlights an additional important atypical presentation of giant hiatal hernias. While shortness of breath and wheezing typically portends a consideration of bronchial asthma, it is important to consider that they may be representative of an underlying hiatal hernia, particularly in elderly patients with new-onset wheezing.

\section{Conclusions}

A giant hiatal hernia is a rarely encountered entity with an apparent trend towards atypical presentations in elderly female patients. We highlight a unique presentation of a patient with recurrent episodes of 
wheezing, previously being treated for a number of years as poorly controlled asthma, later discovered to have a giant hiatal hernia. With lifestyle changes and conservative management, the patient has had no further recurrences of her symptoms. This case serves to highlight the heterogeneity of presentations of giant hiatal hernias, particularly for elderly patients, representing a diagnostic and therapeutic conundrum for this patient population. Furthermore, although pulmonary causes are frequently the attributed cause of wheezing, clinicians must be prudent to include both cardiac and gastrointestinal causes in the differential, particularly for elderly patients.

\section{Additional Information \\ Disclosures}

Human subjects: Consent was obtained or waived by all participants in this study. Conflicts of interest: In compliance with the ICMJE uniform disclosure form, all authors declare the following: Payment/services info: All authors have declared that no financial support was received from any organization for the submitted work. Financial relationships: All authors have declared that they have no financial relationships at present or within the previous three years with any organizations that might have an interest in the submitted work. Other relationships: All authors have declared that there are no other relationships or activities that could appear to have influenced the submitted work.

\section{References}

1. Roman S, Kahrilas PJ: The diagnosis and management of hiatus hernia. BMJ. 2014, 349:10.1136/bmj.g6154

2. Mitiek MO, Andrade RS: Giant hiatal hernia. Ann Thorac Surg. 2010, 89:2168-73. 10.1016/j.athoracsur.2010.03.022

3. Mirdamadi SA, Arasteh M: Hiatal hernia: an unusual presentation of dyspnea. N Am J Med Sci. 2010, 2:3956.

4. Torres D, Parrinello G, Cardillo M, Bellanca M, Licata G: Hiatal herniation of the stomach and pancreas in a patient with oxygen desaturations. Libyan J Med. 2013, 8: 10.3402/ljm.v8i0.23288

5. Chou CJ, Su HM: An unusual cause of dyspnea: giant hiatal hernia followed by Takotsubo cardiomyopathy . Kaohsiung J Med Sci. 2014, 30:484-5. 10.1016/j.kjms.2014.02.006

6. Sahin C, Akın F, Cullu N, Özseker B, Kirli İ, Altun İ: A large intra-abdominal hiatal hernia as a rare cause of dyspnea. Case Rep Cardiol. 2015, 2015: 10.1155/2015/546395

7. Wongrakpanich S, Hassidim H, Chaiwatcharayut W, Manatsathit W: A case of giant hiatal hernia in an elderly patient: when stomach, duodenum, colon, and pancreas slide into thorax. J Clin Gerontol Geriatr. 2016, 7:112-4. 10.1016/j.jcgg.2015.06.002

8. Wirsching A, Klevebro F, Boshier PR, Hubka M, Kuppusamy MK, Kirtland SH, Low DE: The other explanation for dyspnea: giant paraesophageal hiatal hernia repair routinely improves pulmonary function. Dis Esophagus. 2019, 32:10.1093/dote/doz032

9. Vardar R, Keskin M, Valitova E, Bayrakci B, Yildirim E, Bor S: Effect of alginate in patients with GERD hiatal hernia matters. Dis Esophagus. 2017, 30:1-7. 10.1093/dote/dox039

10. Siu CW, Jim MH, Ho HH, Chu F, Chan HW, Lau CP, Tse HF: Recurrent acute heart failure caused by sliding hiatus hernia. Postgrad Med J. 2005, 81:268-9. 10.1136/pgmj.2004.023416 